\title{
An opportunity missed: tax alcohol itself
}

I welcomed the Chancellor's decision to raise alcohol duty in the recent and coming budgets above the rate of inflation commenting that it was but a small step in the fight against alcohol abuse.

Charles replied, 'As you know I am opposed to the abuse of taxation to manipulate behaviour rather than its prime purpose to raise revenue, but I do accept there is a strong case here. Furthermore if you are in favour of this approach, an opportunity has been missed.'

'Taxing alcopops highly? I heard the Chancellor say on the radio that it is illegal under common market rules to subsidise one form of drinking with another!'

'And, Coe, he also said quite correctly that that would be shutting the door after the horse had bolted, as young people are drifting away from these drinks. His statement about common market rules was, however, either nonsense or he is already defying the law!'

'Why?' and after a moment's thought I added, 'Of course he and his predecessors have always favoured beer drinkers!'

'And the beer industry itself, Coe, but the difference has narrowed recently, partly because of the increase in the alcohol concentration of many wines. Industry lobbying has also ensured that the premium against spirits has fallen in recent years.

The system is not only complicated but inconsistent, some rates of duty are flat, for example almost all table wines and cider, others banded, and some determined by percentage alcohol, for example beer and spirits, albeit at different rates.'

'What is the overall effect of this? I understand that champagne is specifically targeted!'

'Strictly sparkling wines with enough sparkle. I do not know how the line is drawn!

But to answer your question in rough terms, drinkers of German wine are subsidising spirit drinkers who subsidise champagne drinkers who subsidise beer and new world wine drinkers who subsidise cider drinkers...'

'Enough subsidy to ruffle the feathers of all the mandarins of Brussels I would have thought! I intervened.
'Surprisingly not!' Charles replied and returning to the main theme continued, 'The solution is simple, but the chance was missed in the budget: treat all drinks in the same way as spirits and tax the alcohol content itself irrespective of the product. This would be fiscal justice in addition to any health benefits.'

'What would the latter be?'

'I think the most important is just simply the message that it is the alcohol content that matters. In practice I think the cost deterrent will always be small because unlike tobacco there is no justification for penal taxation with a view to eliminating consumption. Even if you disagree one has to be realistic about the potential loss of revenue if such taxation were introduced suddenly. To enhance the health message it is absolutely essential to ensure that, although the total take might increase, the price of some products would fall.'

'With table wines now varying from under seven per cent to over 15 , surely that would be easy.'

'Indeed it would, and that leads to another potential benefit for regular wine drinkers, a reduction in the increasing risk of heavy drinking simply by dint of the increase in alcohol content of some table wines. Again this would follow principally from increased awareness of the alcohol content rather than price. At the upper end of the market the duty on wines is such a low proportion of the cost that the change would hardly matter.'

'On the other hand at the lower end where there has been a move from beer to wine it might really count!'

'True, but it is at this end of the market where the biggest price problem with both alcohol and tobacco operates that is both personal and illicit purchasing abroad for onward sale. Duty is a tax which distorts the relative prices of products. A common market which allows duty to be applied differently across its various geographical areas is a contradiction in terms. Until uniform rates of duty are applied throughout the European Community (EC) the potential for influencing behaviour by raising them is severely limited, though a stricter definition of 'for personal use' might help.'

'I have never understood why the government has not tightened up on this to the benefit of the 
nation's health and local shopkeepers, let alone its own revenue.'

'Political expediency I am afraid. The shopping of the holiday maker is sacrosanct; furthermore I can see no chance of the logical requirement for uniform rates of duty throughout the EC ever coming to fruition. On the other hand, wine and beer duty rates are now sufficiently close to remove the political difficulty so the Chancellor should take the opportunity to tax alcohol by per cent content at the next budget. I can see no reasons against this other than fiscal inertia and the treasury's delight in complicated taxes.'

Perhaps there is just a chance that this, or some future, Chancellor will see the sense in this argument. If so, I am sure Charles would join with me in toasting him with a (slightly) cheaper glass of champagne! 